\title{
RARE PRIMARY CRANIOFACIAL CLEFTS: PATTERN, CHALLENGES, AND MANAGEMENT IN A NIGERIAN POPULATION
}

\author{
Rowland Agbara' ${ }^{1}$, Benedict 0. Akintububo ${ }^{2}$, Benjamin Fomete ${ }^{3}$, Kelvin U. Omeje ${ }^{4}$, Yusuf T. Sambo ${ }^{2}$, Ngeh Mangai', \\ Enoch A. Idowu ${ }^{5}$ \\ 'University of Jos/Jos University Teaching Hospital, Nigeria \\ ${ }^{2}$ Federal Teaching Hospital Gombe, Nigeria \\ ${ }^{3}$ Ahmadu Bello University/Ahmadu Bello University Teaching Hospital, Nigeria \\ ${ }^{4}$ Bayero University/Aminu Kano Teaching Hospital, Nigeria \\ ${ }^{5}$ Faculty of Dentistry, University of Jos, Nigeria
}

\begin{abstract}
INTRODUCTION: There is inconsistent clinical presentation of rare orofacial clefts, and its low number has resulted in most studies on rare craniofacial clefts to be retrospective in nature, with significant amount published as case reports. ОвJеCTIVES: To study the pattern, challenges, and management of rare craniofacial clefts in a Nigerian population. MATERIAL AND METHODS: This is a retrospective observational study of patients with rare facial clefts, who visited private health institutions between January 2009 and August 2018. Data retrieved was analyzed using statistical package for social sciences (SPSS), version 16 (SPSS Inc., Chicago, IL, USA).

RESULTS: Of the 899 patients who presented with orofacial clefts within the reviewed period, a total of 20 patients had rare facial clefts, with typical to rare craniofacial cleft ratio of $46.3: 1$. The prevalence rate of rare craniofacial cleft was 22.2 per 1,000 cases. Age of patients ranged from 0.04 to 37.00 years, with median age of $3.50 \pm 36.96$ years. There were 10 males and 10 females, with male to female ratio of $1: 1$. Tessier number 0 had the highest frequency $(n=9,36.0 \%)$, followed by Tessier number $7(n=3,12.0 \%)$ and $2(n=3,12.0 \%)$. Repair was achieved using local tissue advancement and direct closure techniques under general anesthesia in 10 patients and local anesthesia in 6 patients. Coloboma of the eyelid was the most common abnormality noted.

Conclusions: The prevalence of rare craniofacial clefts is low in this environment and Tessier 0 cleft is the commonest type seen. Treatment is generally challenging due to inadequate manpower.
\end{abstract}

KEY WORDS: craniofacial abnormalities, health resources, local advancement, surgery.

J Stoma 2020; 73, 5: 240-245

DOI: https://doi.org/10.5114/jos.2020.100547

\section{INTRODUCTION}

Human face is composed of all tissue types (epithelial, connective, neural, vascular, and osseous tissues), and its embryological development involves complex interactions both at the macroscopic and molecular levels. Any disturbance in these complex interactions may result in abnormal tissue development. Because orofacial structures are important for aesthetics and functions, abnormal orofacial tissue development can be associated

\section{JOURNAL OF} STOMATOLOGY CZASOPISMO STOMATOLOGICZNE

AdDress FOR CORRESPONDENCE: Rowland Agbara, Department of Oral/ Maxillofacial Surgery, University of Jos/Jos University Teaching Hospital, Plateau state, P.M.B. 2076, Nigeria, e-mail: row_prof@yahoo.com 
with severe aesthetic, functional, and psychological complications. Orofacial cleft is the most common congenital anomaly seen worldwide, with its incidence varying among different reports. Presently, organizations, such as Smile Train and Operation Smile, support free cleft surgeries all over the world because of the burden of this disease in addition to cultural practices that promote stigmatization of cleft patients and their families.

Both genetic and environmental factors have been implicated in its etiology. Genetic influence is noted in many syndromes that have craniofacial cleft as a part of their phenotype, and these genetic anomalies involve chromosomal rearrangements, such as trisomies, duplications, deletions, micro-deletions, or cryptic rearrangements [1]. Environmental factors associated with craniofacial cleft include radiation exposure, maternal infection, maternal metabolic imbalances, drugs, and chemicals [2].

Clinical presentation of craniofacial cleft is inconsistent, and it can appear as usual or common simple defects of the lip, alveolus, nose, or palate. However, in some cases, it may present as rare craniofacial clefts with varying degree of severity. These rare cases can present a great challenge to a surgeon. The reported incidence of craniofacial cleft is 1.43 to 4.85 per 100,000 live births [3].

Rare and complex craniofacial clefts have been diversely classified, and each of these classifications has its merits and drawbacks. No single classification accurately describes all the different types of craniofacial cleft [4]. Classifications of rare craniofacial clefts are defined by the American Association of Cleft Palate Rehabilitation, Boo-Chai, DeMeyer, Karfik, Van der Meulen, Tessier, Fearon, and Bangalore classifications. However, the Tessier classification is the most widely accepted because it incorporates the underlying skeletal defect, relates the cleft to neighboring deformities, and is treatment-oriented; although, it does not associate the defect with embryological development and rare craniofacial clefts occurring in a discontinuous line.

Patients with craniofacial cleft may require series of treatment from the time of birth to adulthood [5], and the timing for initial surgery varies among centers all over the world. This is influenced by the type of orofacial cleft, presence of other congenital anomalies, availability of medical facilities, surgeons' skills, and preferences among other factors. However, the treatment of a craniofacial cleft should be initiated soon after birth and continued up to adulthood, and should involve interdisciplinary team approach whenever feasible [6]. Limited studies have provided answers to the pattern of rare craniofacial clefts in a Nigerian population. This study will allow for comparison with studies from different parts of the world, highlighting peculiarities in this environment.

\section{OBJECTIVES}

The aim of the present study was to describe the pattern of rare craniofacial clefts in a particular region of
Nigeria observed in patients treated in private health facilities that offers free cleft surgeries, and to highlight the challenges of management.

\section{MATERIAL AND METHODS}

All craniofacial clefts cases seen in two private specialist health facilities (795 cases between January 2000 and September 2018; 105 cases between November 2015 and September 2018) were reviewed for cases with rare craniofacial clefts. Craniofacial cleft repair was performed (free of charge) in these two private health facilities with partial support from Smile Train. Information retrieved from patients' case-notes and operating theatre records included age, sex, clefts risk factors, type of cleft, clinical features, abnormalities associated, and surgery. A rare craniofacial cleft was classified based on Tessier classification. None of the patients had computed tomography (CT) scan performed. Data retrieved was subjected to statistical analysis involving frequencies (count, percent), rates of central tendency (mean), and measures of dispersion (standard deviation) using statistical package for social sciences (SPSS), version 16 (SPSS Inc., Chicago, IL, USA). Findings from this descriptive statistics were characterized in the form of tables and charts.

\section{RESULTS}

\section{AGE/SEX DISTRIBUTION AND RISK FACTORS}

A total of 899 patients presented with a cleft of the orofacial region and of these, 20 patients had rare craniofacial clefts (based on a Tessier classification), with typical to rare craniofacial cleft ratio of $46.3: 1$. Two other patients presented with simple clefts with congenital facial tumors and were excluded from the study, because they did not fit into the Tessier classification. The prevalence rate of rare craniofacial cleft was 22.2 per 1,000 cases. There were 10 males and 10 females, with male to female ratio of $1: 1$. Age of the patients ranged from 0.04 to 37.00 years, with median age of $3.50 \pm 36.96$ years. There were not known associated risk factors for craniofacial clefts in any of the 20 patients studied.

\section{TESSIER CLEFTS AND LOCATION}

Rare craniofacial clefts were located in the right $(n=7,35.00 \%)$ and median $(n=10,50.00 \%)$ facial regions, while 3 cases $(15.00 \%)$ were bilateral. There were 25 Tessier clefts (Figure 1) noted in 20 patients studied, with Tessier number $0(n=9,36.0 \%)$ been the most frequent, followed by Tessier number $7(n=3,12.0 \%)$ and $2(n=3,12.0 \%)$. Of the 20 patients studied, the distribution of Tessier clefts was facial in 16 cases, cranial in 2 cases, and both facial and cranial in 2 cases. Although 


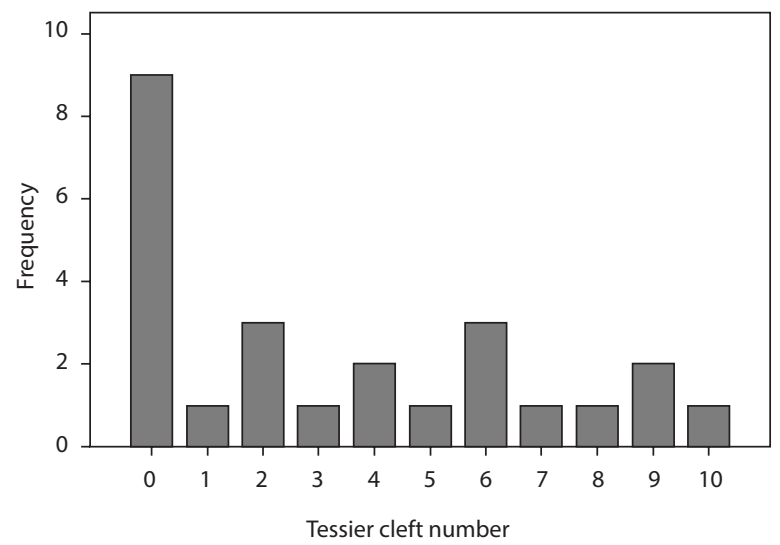

FIGURE 1. Distribution of Tessier cleft in the 20 studied patients

TABLE 1. Associated abnormalities observed among patients with rare craniofacial clefts

\begin{tabular}{|c|c|}
\hline Anomaly & Frequency \\
\hline \multicolumn{2}{|l|}{ Ocular } \\
\hline Orbital dystopia & 3 \\
\hline Eyelid coloboma & 5 \\
\hline Epibulbar dermoid & 1 \\
\hline \multicolumn{2}{|l|}{ Facial } \\
\hline Hemifacial maxillary hypoplasia & 2 \\
\hline Nasal teratoma & 1 \\
\hline Unilateral cleft lip & 1 \\
\hline Cleft of alveolus & 2 \\
\hline Bilateral cleft lip & 1 \\
\hline Cleft palate & 1 \\
\hline Preauricular sinus & 1 \\
\hline \multicolumn{2}{|l|}{ Cranial } \\
\hline Encephalocele & 2 \\
\hline \multicolumn{2}{|l|}{ Orthopedic } \\
\hline Amniotic constriction band of arm & 1 \\
\hline Amputation of toes & 1 \\
\hline Total & 22 \\
\hline
\end{tabular}

three patients presented with more than one type of Tessier clefts, there were only two cases of north- and southbound Tessier clefts (0-14 and 1-13) co-existing together.

\section{CLINICAL FEATURES AND CORRELATED ABNORMALITIES}

Clinical features and correlated abnormalities are presented in Table 1 and of these, ocular manifestations had the highest frequency. In all the patients reviewed, no systemic abnormalities were found clinically, and no imaging modalities were used.

\section{ANESTHETIC TECHNIQUE AND SURGICAL PROCEDURE}

A total of $16(80.0 \%)$ patients had surgical repair and these were performed under local anesthesia ( $2 \%$ xylocaine $+1: 80,0000$ adrenaline) without sedation in $6(37.5 \%)$ cases and general anesthesia in the remaining 10 (62.5\%) patients. All the 16 patients treated had only soft tissue procedures, which mainly involved the use of local advancement flaps and direct closure of the defect, and resulted in fairly acceptable outcomes (Figures 2A-C). The direct closure involved refreshment of the edges of the defect, with primary closure with or without upper sulcular incision in the case of the lip. In wider defects, as seen for example in Tessier number 2 and 3, subperiosteal dissection up to zygomatic bone is undertaken to achieve primary closure.

The remaining four $(20 \%)$ patients were not treated due to complexity of cases and death. Although no rating scale was used in assessing patients' level of satisfaction during follow-up, they were satisfied with the outcomes of the procedures.

\section{DISCUSSION}

Craniofacial cleft is a term describing a defect of either cranial or facial skeleton, or a combination of both, in addition to the overlying soft tissue envelope. They can be typical (common) or atypical, with typical craniofacial clefts (cleft lip and palate) being more common than the atypical craniofacial clefts [7]. Because of their uncommon occurrence, atypical craniofacial clefts are also referred to as rare craniofacial clefts, and they may present with tissue deficiency or excess.

A prevalence rate of 22.2 per 1,000 cases reported in this study is lower than in previous reports $[8,9]$, which can be related to the difference in patient selection, study period, or definition of at-risk group. For example, the use of computed tomography in some studies may have increased the number of Tessier cleft diagnosed. This difference in rate of rare craniofacial clefts might also reflect the regional variation of diseases. Moreover, cultural practices encouraging infanticide can contribute to disparity in rates. Generally, the reported incidence rate of rare craniofacial clefts in the literature vary, ranging from 1.4 to 4.9 per 100,000 live births as reported by Bodin et al. [3], while Fijałkowska and Antoszewski [10] described an incidence rate of 4.95 per 100,000 live births.

The present study revealed no gender predilection in the occurrence of rare craniofacial cleft, which is consistent with previous studies $[8,9,11]$. However, some researchers reported a male predominance $[10,12]$. It may be that certain types of Tessier clefts tend to show gender predilection $[11,12]$.

The wide variation in age of the investigated patients was similar to findings from African studies [8, 11], which was in contrast with other reports where most patients presented less than 2 years $[10,12]$. Delayed presentation 

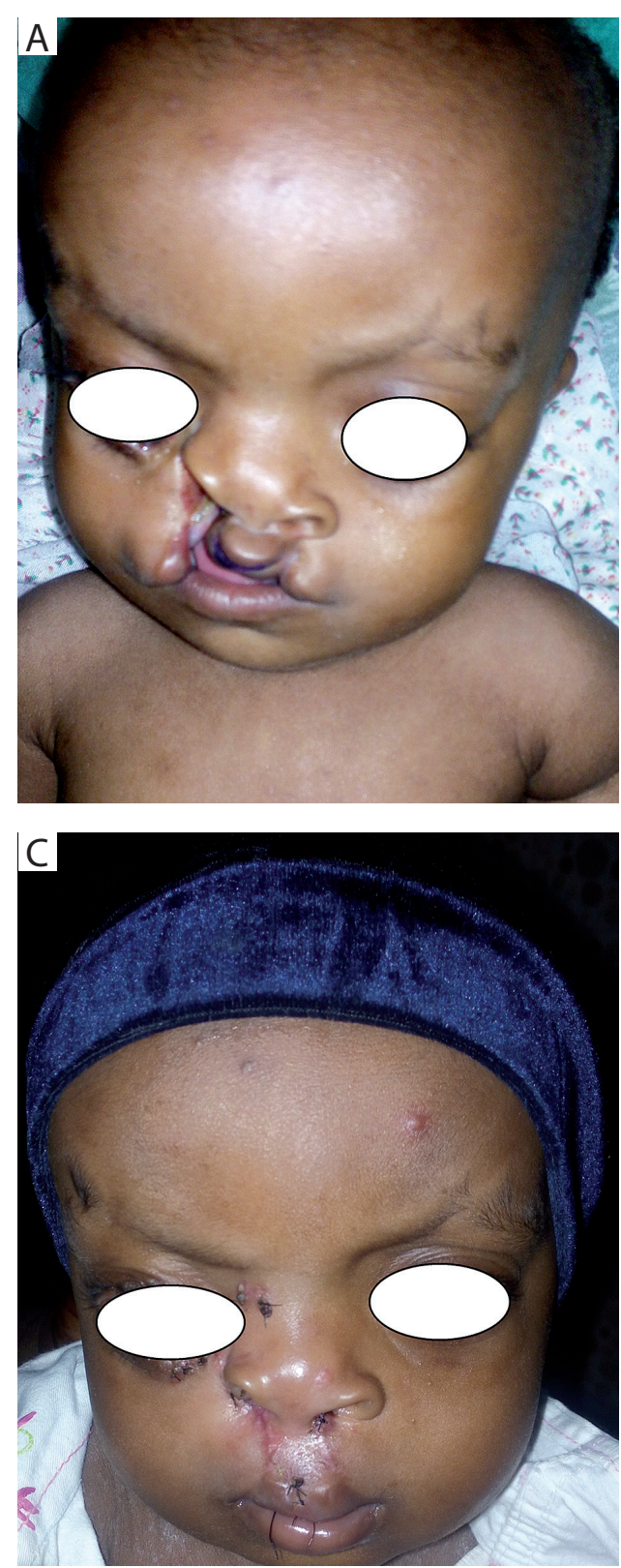

in our environment remains a challenge to achieve optimal care, which is partly due to religious, socio-cultural, and economic factors. This highlights the need for increased awareness campaign and funding to support free surgical treatment.

Both genetic and environmental factors have been implicated in the etiology of rare craniofacial cleft. In terms of genetic predisposition, it has been observed in over 300 syndromes that craniofacial clefts create a part of the phenotype, with Mendelian inheritance of alleles at a single genetic locus accounting for about half of these cases. Furthermore, craniofacial cleft has been noted in several conditions with chromosomal rearrangements, such as trisomies, duplications, deletions, micro-deletions, or cryptic rearrangements [1]. Contributing environmental factors include radiation exposure, maternal infection, maternal metabolic imbalances, and drugs/

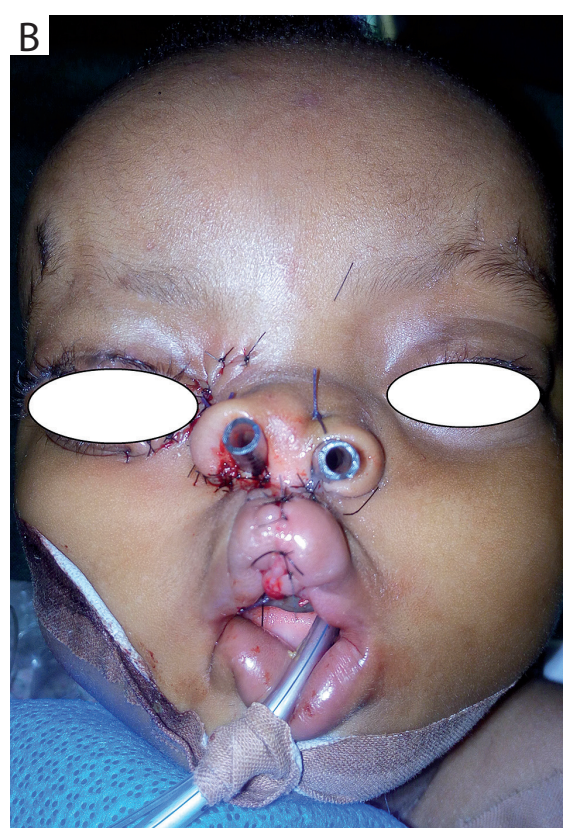

FIGURE 2. Fairly acceptable results in repair of Tessier number 2. A) Pre-operative frontal view with associated amniotic band of left arm. B) Immediate post-operative view. C) The 2-month outcomes review

chemicals [2]. In our study, none of the 20 patients had any known risk factors. Similarly, although studies have shown a common etiological factor for non-syndromic cleft lip, and/or plate and cancers, there is no evidence of increased cancer risk in patients with cleft or their first-degree relatives $[13,14]$.

Findings from different studies have demonstrated that certain Tessier clefts occur commonly than others. In the present study, Tessier number 0 cleft had the highest frequency of occurrence among the investigated patients. Moreover, Tessier number 0 has been reported $[9,11,15]$ as the commonest type of rare craniofacial clefts. Other studies reported a preponderance of Tessier number 1 and 6 clefts $[8,10]$, respectively. Analysis of both large and small series of studies on rare craniofacial clefts could assist in obtaining the actual picture of the frequency of occurrence of the different types of Tessier clefts. 
Rare craniofacial clefts may occur separately or in association with common craniofacial clefts, and may show a syndromic or non-syndromic pattern. Only one of the patients in the present study had an associated syndrome, i.e., amniotic band syndrome. Disorders associated with rare craniofacial clefts include Treacher-Collins and Gardner's syndromes, and hemifacial microsomia. In a review of 66 craniofacial clefts [11], half of the patients were observed to have associated syndrome, of which holoprosencephaly was the most common disorder. However, other studies $[8,10]$, reported no associated syndromes.

Rare craniofacial clefts may be associated with local (head/neck) and systemic anomalies, including anophthalmia, choanal atresia, absence of the lacrimal system, maxillary hypoplasia, polydontia, and cardiovascular (such as quadricuspid aortic valve and single coronary artery) and renal defects (e.g. solitary kidney) $[12,16]$. Ocular abnormalities were the most common anomalies in the present study, and this was similar to previous reports $[8,12]$. The association of clefts generally with other systemic irregularities underlines the need for adequate preoperative assessment, especially by pediatricians and other specialists. This would ensure safe anesthesia and avoidance of preventable complications, such as blindness.

Currently, different imaging modalities are available, enabling diagnosis and surgical planning, and include three-dimensional ultrasound, plain radiography, computed tomography, and magnetic resonance imaging. Three-dimensional ultrasound and fetal magnetic resonance imaging are useful in prenatal diagnosis of rare craniofacial clefts, which facilitate parental counseling, early postnatal intervention, or in some severe cases, a possible termination of pregnancy [17]. However, plain radiography is less satisfactory for patient's evaluation. In the present study, imaging modalities were not used in the reviewed patients, which was principally related to the inability of these patients to afford the cost, since they were usually of a low socio-economic class.

The treatment of rare craniofacial clefts involves a series of staged complex surgeries, performed from childhood to adulthood, and depending on the nature of deformity. Wherever feasible, a multidisciplinary approach should be implemented involving maxillofacial surgeon (or plastic surgeon), neurosurgeon, ophthalmologist, and orthodontist. A multidisciplinary approach is usually difficult in this environment, due to paucity of specialists and limited funding. It has been recommended that surgical correction of soft tissue defects should be undertaken within one year of a child life, revision surgeries around four years, while skeletal deformities should be performed above the age of sixteen [18]. However, the treatment should be individualized, depending on the presentation [10]. For example, in some patients, corneal protection surgery can be of the initial priority. Moreover, in this environment, patients with Tessier clefts may present to the hospital late in ad- olescence or adulthood, due to unawareness of free cleft surgical programs.

Soft tissue procedures include direct closure, use of local flaps or expanded tissues, and microvascular soft tissues transfer $[8,12,19,20]$, using Tessier, modified Tessier, and Kawamoto techniques. In the present study, the direct closure and use of local flaps were utilized. Skeletal procedures, which might be required in patients with rare craniofacial clefts involve bone grafting (using calvaria, rib, or iliac bone), distraction osteogenesis, and Le Fort osteotomy $[12,21,22]$. In the present study, no patient received a skeletal surgical procedure, which was due to loss to follow-up after soft tissue procedures. Therefore, long-term review of these patients was extremely difficult.

\section{CONCLUSIONS}

Rare craniofacial clefts are uncommon in this environment and the treatment is negatively influenced by socio-cultural factors, lack of multidisciplinary approach due to shortage of specialists, and loss to follow-up review. However, the use of local tissue advancement and direct closure enable to achieve fairly acceptable results.

\section{ACKNOWLEDGEMENT}

We would like to thank Smile Train for supporting free cleft surgeries in these private health facilities.

\section{CONFLICT OF INTEREST}

The authors declare no potential conflicts of interest with respect to the research, authorship, and/or publication of this article.

\section{References}

1. Brewer C, Holloway S, Zawalnyski P, et al. A chromosomal deletion map of human malformations. Am J Hum Genet 1998; 63: 1153-1159.

2. Kawamoto HK, Wang M, Macomber B. Rare craniofacial clefts. In: Reconstructive Plastic Surgery. Converse JM. $2^{\text {nd }}$ ed. Philadelphia: W.B. Saunders Co; 1977, pp. 1-32.

3. Bodin F, Salazard B, Bardot J, Magalon G. Craniofacial cleft: a case of Tessier no. 3, 7 and 11 cleft. J Plast Reconstr Aesthet Surg 2006; 59: $1388-1390$.

4. Eppley BL, van Aalst JA, Robey A, Havlik RJ, Sadove AM. The spectrum of orofacial clefting. Plast Reconstr Surg 2005; 115: 101e-114e.

5. McIntyre GT. Management of patients with non-syndromic clefts of the lip and/or palate. Part 2: From primary surgery to alveolar bone grafting. Dent Update 2014; 41: 775-782.

6. Freitas JA, Garib DB, Oliveira TM, et al. Rehabilitative treatment of cleft lip and palate: experience of the Hospital for Rehabilitation of Craniofacial Anomalies - USP (HRAC-USP) - Part 2: Pediatric dentistry and orthodontics. J Appl Oral Sci 2012; 20: 268-281.

7. Resnick JI, Kawamoto HK Jr. Rare craniofacial clefts: Tessier no. 4 clefts. Plast Reconstr Surg 1990; 85: 843-849; discussion 850-852. 
8. Bello SA, Ibikari AB, Oketade I, Balogun SA. Atypical facial clefts from Northcentral Nigeria, review of 36 cases. Cleft Palate Craniofac J 2019; 56: 514-520.

9. Kalantar-Hormozi A, Abbaszadeh-Kasbi A, Goravanchi F, Davai NR. Prevalence of rare craniofacial clefts. J Craniofac Surg 2017; 28: e467-e470.

10. Fijałkowska M, Antoszewski B. Rare facial clefts. Pol Przegl Chir 2015; 87: 389-394.

11. Tshimbila Kabangu JMV, Andrew MH, George WG. Demographic and clinical profile of craniofacial clefts at Comprehensive Rehabilitation Service in Uganda. Afr J Health 2018; DOI: 10.26875/ajhi112017vi.

12. Alonso N, Freitas Rda S, de Oliveira e Cruz GA, Goldenberg D, Dalloglio Tolazzi AR. Tessier no. 4 facial cleft: evolution of surgical treatment in a large series of patients. Plast Reconstr Surg 2008; 122: 1505-1513.

13. Bille C, Winther JF, Bautz A, Murray JC, Olsen J, Christensen K. Cancer risk in persons with oral cleft - a population-based study of 8,093 cases. Am J Epidemiol 2005; 161: 1047-1055.

14. Lima LS, Silvério Mde O, Swerts MS, et al. Frequency of cancer in first-degree relatives of patients with cleft lip and/or palate in the Brazilian population. Braz Dent J 2013; 24: 200-203.

15. da Silva Freitas R, Alonso N, Shin JH, Busato L, Ono MC, Cruz GA Surgical correction of Tessier number 0 cleft. J Craniofac Surg 2008; 19: 1348-1352.

16. Al-Mehisen R, Essely RE, Al-Mallah M, Al-Mohaissen MA, Kashour T. Quadricuspid aortic valve, single coronary artery, solitary kidney and oblique facial cleft. A unique constellation of congenital abnormalities: case report and review of the literature. J Genet Syndr Gene Ther 2016; 7: 291.

17. Cavaco-Gomes J, Duarte C, Pereira E, Matias A, Montenegro N, Merz E. Prenatal ultrasound diagnosis of Tessier number 7 cleft: case report and review of the literature. J Obstet Gynaecol 2017; 37: 421-427.

18. Versnel SL, van den Elzen ME, Wolvius EB, et al. Long-term results after 40 years' experience with treatment of rare facial clefts: Part 1 - oblique and paramedian clefts. J Plast Reconstr Aesthet Surg 2011; 64: 1334-1343.

19. Afifi AM, Djohan R, Sweeney W, et al. Long-term follow-up of a Tessier number 5 facial cleft. Craniomaxillofac Trauma Reconstr 2011; 4: 35-42.

20. Ueda K, Shigemura Y, Nuri T, et al. A case of complex facial clefts treated with staged-tissue expansion. Plast Reconstr Surg Glob Open 2015; 2: e264.

21. Tuncbilek G, Alanay Y, Kayikcioğlu A. Le Fort III bipartition osteotomy to treat a rare craniofacial anomaly: frontofacionasal dysostosis. J Craniofac Surg 2009; 20: 1056-1058.

22. Chauhan DS, Guruprasad Y. Goldenhar syndrome with Tessier's 7 cleft: report of a case. J Maxillofac Oral Surg 2011; 14 (Suppl 1): $42-46$. 